\title{
COMPARATIVE ANALYSIS OF THE USE OF MODERATE-ALTITUDE TRAINING BY TOP RUSSIAN AND CHINESE ATHLETES
}

\author{
EVGENY MYAKINCHENKO1, GAO BINGHONG², MIKHAIL SHESTAKOV1 \\ ITraining Center of the Russian National Teams, Analitical Department, Moscow, Russia \\ 2Shanghai University of Sport, School of Physical Education and Training, China \\ Mailing address: Mikhail Shestakov, Training Center of the Russian National Teams, \\ Analitical Department, Moscow 105064, Russia, e-mail: mshtv@mail.ru
}

\begin{abstract}
Introduction. The aim of our work was to study the effect of natural hypoxia applied by elite athletes in the course of common training. Data analysed in this paper were collected during joint Russian-Chinese research on the training of elite athletes, who were members of the Russian national team (8 male biathletes, B-team) and 2016 Chinese Olympic team (12 female rowers, Rteam). Material and methods. The study was held in the preparatory period, which lasted 4-5 months. The preparatory period in each team was divided into two stages. In the R-team, in the first stage, a training camp was organised at sea level (SL) (200 $\mathrm{m}, 57$ days), and in the second stage, an altitude camp (AC) was held at 2,280 m (40 days). In the B-team, in the first stage, two training camps were held: the first one at 1,100 m (AC, June-July, 19 days) and the second one, a sea level camp (SLC), at $140 \mathrm{~m}$ (July-August, 31 days). Thus, the second control test was preceded by 31-day-long training at SL. In the second stage (SeptemberOctober), three training camps were held: the first one at 1,100 m (AC, 19 days), the second one at $150 \mathrm{~m}$ (SLC, 13 days), and the third one at 1,100-2,800 m (AC, 11 days). Both teams underwent three control tests: prior to the first training stage, at the end of the first training stage, and 6-8 days after the end of the second training stage. All control tests were performed at SL. Results. Monitoring of elite athletes' training in the preparatory period showed positive changes in physical preparedness in both groups. However, we found that those positive changes might not be related to an additional effect of natural hypoxia. Conclusion. Our study has shown that rational and well-balanced planning according to training goals is the key factor in improving general and specific athletic preparedness.
\end{abstract}

Key words: hypoxic training, elite athletes, endurance sports

\section{Introduction}

Altitude or hypoxic training has been adopted by elite athletes in their training programmes all over the world and has been proven to be effective. However, sport specialists are still discussing various issues related to training at altitude. The results of multiple investigations on the effects of altitude training on athletic performance in elite athletes have been reviewed in previous studies [1-11].

Many sport scientists have reported that training under natural or artificial hypoxia enhances endurance performance through the influence of specific factors. Nevertheless, a thorough analysis of relevant studies has shown a lack of valid data related to the positive effect of hypoxic training on top sport results $[6,7]$. There are several factors which may be responsible for this phenomenon:

First of all, even when statistics show no valid positive alterations in an experimental group compared with a control group, explaining the results can be much more complicated. For instance, if 10 athletes performed similar hypoxic training, it might have been very effective for 2-3 of them and exerted a negative effect on the other 2-3 persons, while 4-5 athletes demonstrated insignificant positive changes in performance tests [1, 8].

Many unforeseen factors may influence sport performance outcomes, which makes the results of comparative studies less reliable [12].

Positive changes have been observed in the respiratory and cardiovascular systems after training at the altitude of 2,200-
2,500 m, while to improve local factors, training should be held at an altitude of up to 3,100 $\mathrm{m}$ (provided training is of maximal and submaximal intensity). However, even top athletes can hardly reach the maximal intensity of muscular contraction in sport-specific exercises at such an altitude. Consequently, prolonged training in that regimen hampers athletic performance $[2,5,6]$.

Uniform training loads and identical characteristics of subjects are crucial issues in any study in sport science. These requirements are unrealistic when we study elite athletes preparing for athletic competitions.

Furthermore, many hypoxia-induced adaptive changes in the human organism are similar to those resulting from sealevel athletic training. Thus, it is very difficult to distinguish the effect of altitude training on sport performance in elite athletes. Such a complex task cannot be solved with the help of statistical techniques.

In light of the above, the aim of our work was to study the effect of natural hypoxia applied by elite athletes in the course of common training. Data were collected during joint RussianChinese research on the training of elite athletes, who were members of the Russian and Chinese national teams.

\section{Subjects}

\section{Methods}

The participants of the study were 12 female rowers from the 2016 Chinese Olympic team (R-team) and 8 male biathletes from the Russian national team (B-team). All the athletes regularly participated in the World Cup and domestic competitions 
at the national level. The research was approved by the ethics committees of the Shanghai University of Sport, and all participants gave their written informed consent. The characteristics of the subjects are presented in Table 1.

Table 1. Subject characteristics

\begin{tabular}{|c|c|c|c|}
\hline Team & Height $(\mathrm{cm})$ & Weight $(\mathrm{kg})$ & Age $(\mathbf{y})$ \\
\hline Rowers & $180.9 \pm 2.70$ & $74.1 \pm 2.50$ & $23.8 \pm 1.50$ \\
\hline Biathletes & $176.2 \pm 4.48$ & $72.6 \pm 4.91$ & $25.9 \pm 1.51$ \\
\hline
\end{tabular}

\section{Schedule of training camps and control tests}

The study was held in the preparatory period, which lasted 4-5 months. The duration of the training camps, the altitudes at which they were held, and the schedule of control tests are presented in Figures 1 (R-team) and 2 (B-team).

The preparatory period in each team was divided into two stages. In the R-team, in the first stage, a training camp was organised at sea level (SL) (200 m, November-January, 57 days); in the second stage, an altitude camp (AC) was held at 2,280 $\mathrm{m}$ (January-March, 40 days). In the B-team, in the first stage, two training camps were held: the first one at 1,100 m (AC, June-July, 19 days) and the second one, a sea level camp (SLC), at $140 \mathrm{~m}$ (July-August, 31 days). Thus, the second control test was preceded by 31-day-long training at SL. In the second stage (September-October), three training camps were held: the first one at 1,100 $\mathrm{m}$ (AC, 19 days), the second one at $150 \mathrm{~m}$ (SLC, 13 days), and the third one at 1,100-2,800 m (AC, 11 days). The "live low - train high" (LLTH) strategy was applied in the third AC: the athletes stayed at $1,100 \mathrm{~m}$ and completed 5 aerobic workouts at 2,800 $\mathrm{m}$. The training load between the two ACs was low due to the athletes' participation in a competition and the following 6-day-long rest. Therefore, the second stage in the B-team can be regarded as altitude training (similarly as in the R-team).

Both teams underwent three control tests. The first one took place prior to the first training stage, the second one was conducted at the end of the first training stage, and the third one was carried out 6-8 days after the end of the second training stage. All control tests were performed at SL.

\section{Monitoring of training loads}

Similar parameters of training loads were recorded daily in both teams during the pre-altitude and altitude training camps (SLCs and ACs).

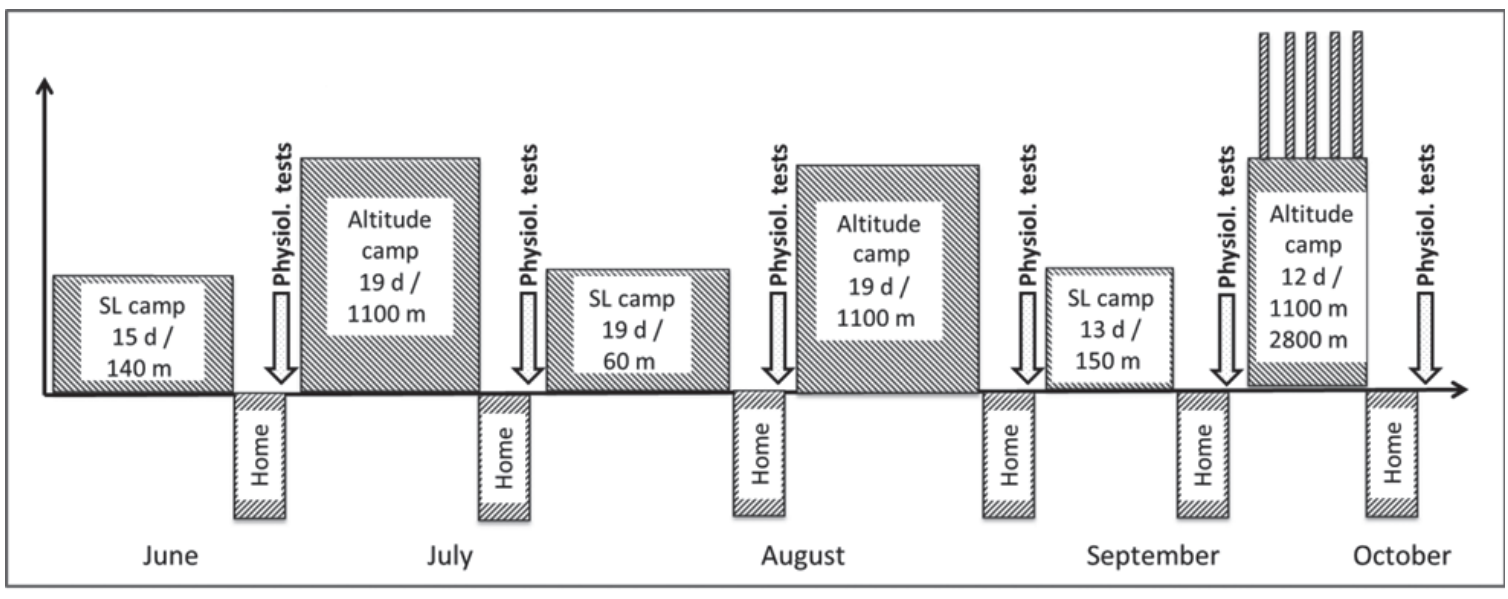

Figure 1. Schedule of sea level and altitude camps of B-team

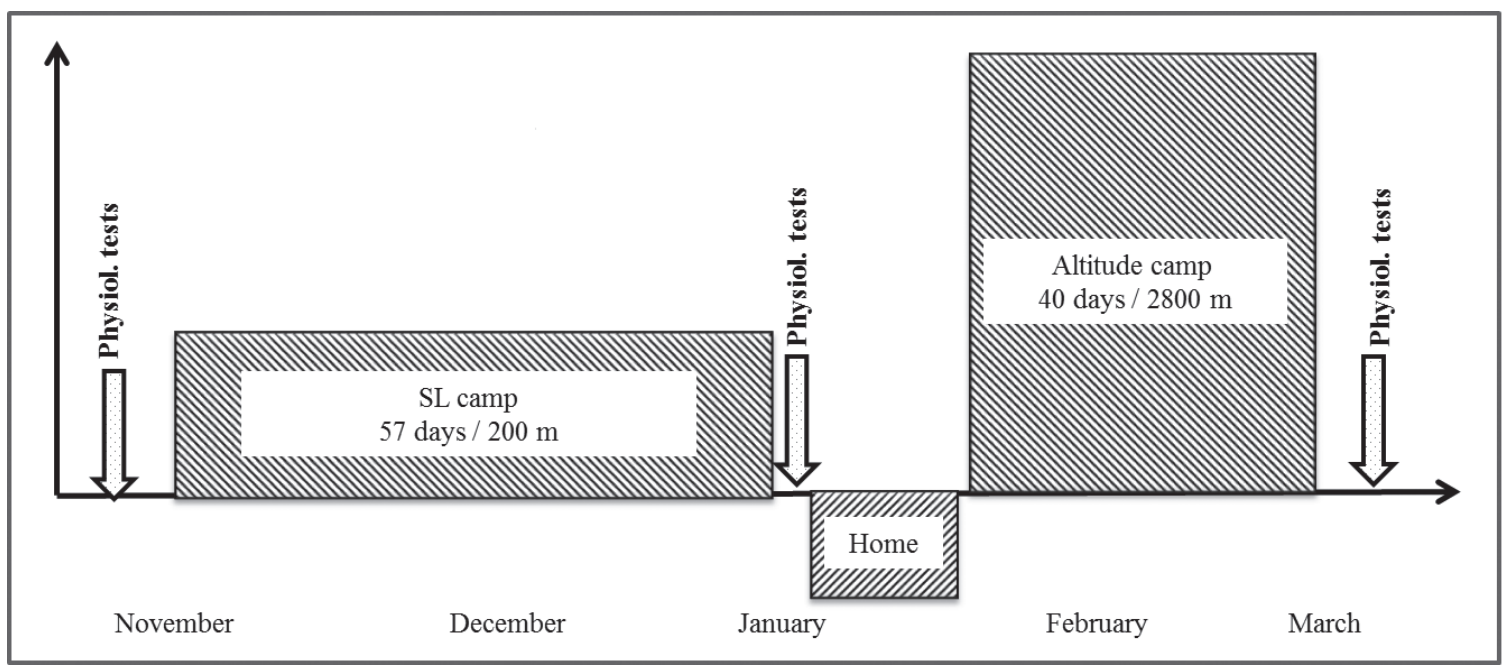

Figure 2. Schedule of sea level and altitude camps of R-team 


\section{Endurance training (hours) R-team}

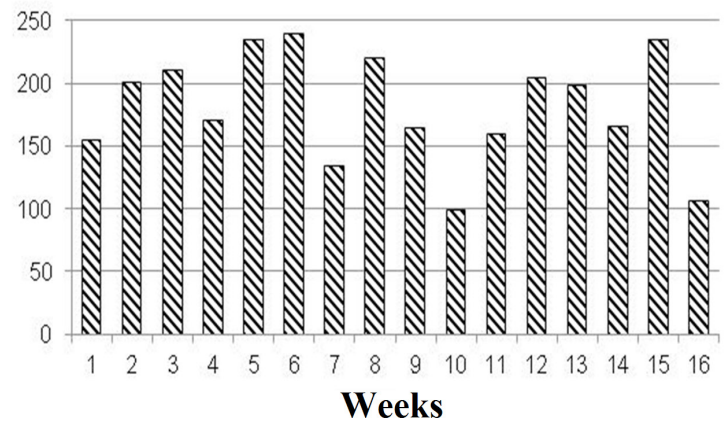

Strenght training (min)

R-team

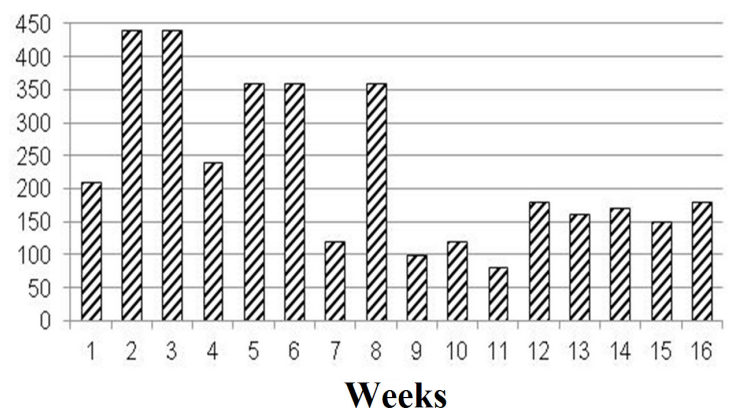

\section{Endurance training (hours) B-team}

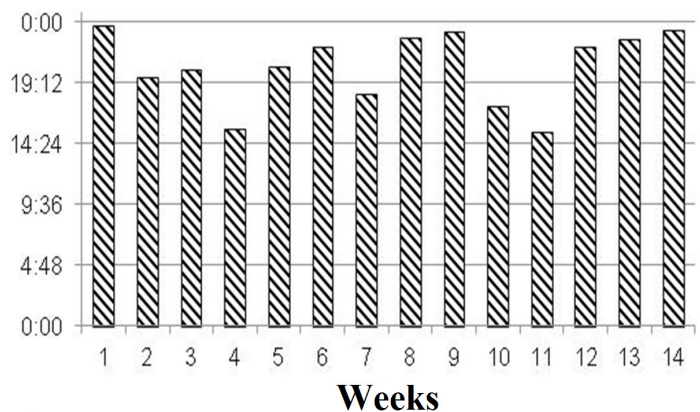

Strenght training (min) B-team

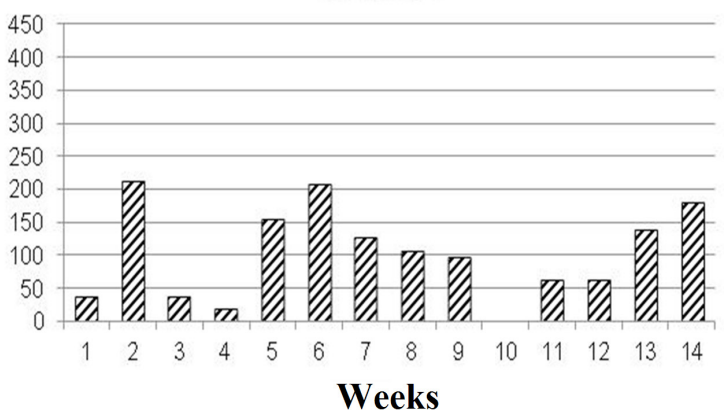

Figure 3. Volumes of endurance and strength exercise in R-team and B-team in first and second training stages

Table 2 presents average training loads per week in the R-team during the SLC (first stage) and AC (second stage). Average training loads completed weekly by B-team in the first and second training stages are presented in Table 3.

The distribution of endurance and strength training loads in the first and second stages is illustrated in Figure 3.

\section{Control tests}

Control testing was planned by Russian and Chinese specialists, and a uniform test protocol was implemented.

The testing procedure in the R-team included a 5-step graded exercise test until exhaustion on a Concept II rowing ergometer. The duration of each step was $4 \mathrm{~min}$; the intervals between the steps, during which blood lactate was measured, lasted 30 seconds. Initial workload was set at $150 \mathrm{~W}$ and increased progressively by $50 \mathrm{~W}$ at each step. Heart rate was measured during the test. Capillary blood was collected (Chronolab systems, Spain) at the $3^{\text {rd }}, 5^{\text {th }}$, and $15^{\text {th }}$ minutes of recovery after the test. The maximal value of La was taken into account.

The graded exercise test provided data for plotting the power-La and power-HR graphs. The graphical method made it possible to determine HR at a standard workload of $250 \mathrm{~W}$ and power output at $4 \mathrm{mM} \mathrm{La}$ (the onset of blood lactate accumulation, OBLA). The first parameter (HR) helped assess changes in the cardiovascular system, and the second one was used to evaluate the changes in power at OBLA.

A maximal 2-km ERG test was performed on the Concept II rowing ergometer before and 2 weeks after AC (not concurrently with the graded exercise test). Time was recorded. A standard 15-min warm-up preceded the test. Blood lactate was measured after the test.

The first test in the B-team was completed two days before the first training stage, the second one two days before the second training stage, and the final one seven days after the third AC. All athletes were tested in the same laboratory at an altitude of $130 \mathrm{~m}$ above sea level. The standard battery of tests included anthropometric measurements and assessments of the strength, force-velocity, and power output characteristics of the subjects. Apart from that, the athletes performed two graded exercise tests to determine ventilation anaerobic thresholds (VentAnT): (1) arm work - on a ski ergometer (Concept II SkiErg) and (2) running with ski poles on a standard treadmill. The order and duration of the tests administered are presented in Figure 4.

As far as the testing procedure is concerned, a standard warm-up on a ski ergometer and stretching exercises preceded the first graded exercise test. The SkiErg test started with a 2-minute warm-up phase at $80 \mathrm{~W}$; then the workload increased progressively by $15 \mathrm{~W}$ every minute. Gas analysis parameters were measured continuously with the use of MetaLyzer (Cortex, Germany) and displayed on a computer. At 1.5-2 minutes after the onset of typical changes in the dynamics of ventilation parameters ( $\mathrm{RQ}, \mathrm{VE}-\mathrm{VCO}_{2}, \mathrm{VO}_{2}-\mathrm{VCO}_{2}$, and VE-HR) and $\mathrm{HR}$, which evidenced reaching the aerobic-anaerobic transition zone (or the end of the isocapnic buffering phase), the test was stopped. The athletes then underwent tests which made it possible to determine power output and force-velocity characteristics.

A 10-15-minute-long active rest period preceded the final treadmill test - running with ski poles of comfortable length 


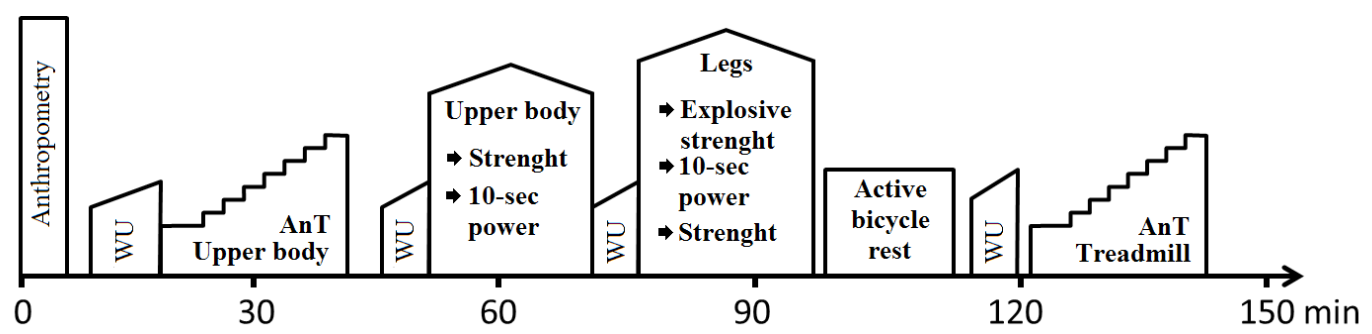

Figure 4. Order and average duration of standard tests procedures used to measure physiological characteristics and motor abilities of male biathletes (B-team) (WU - warm-up, AnT - anaerobic threshold test)'

at increasing speed. The treadmill incline was set at $10 \%$. After a 2-minute warm-up at the initial speed of $6 \mathrm{~km} / \mathrm{h}$, the speed was progressively increased by $0.5 \mathrm{~km} / \mathrm{h}$ every minute. The load was chosen in such a way that the athlete reached the AnT approximately on the $11^{\text {th }}-13^{\text {th }}$ minute of the test. Similarly as in the first graded exercise test, the athletes stopped as soon as they reached the speed of AnT.

The graded exercise tests (ski ergometer and treadmill) provided sufficient data to determine the so-called ventilation anaerobic thresholds (VentAnT) using the VE-HR method (Fig. 5). According to this method, AnT is a point of intersection between the VE-HR curve and a straight line parallel to a linear portion of this curve and passing through a point located $10 \%$ above the point of AeT (i.e. value of VE at the point of deflection of the VE-HR curve). However, the shape was not typical in $10-15 \%$ of the curves. To compensate for random errors, the following techniques were used:

Linear and nonlinear sections of the VE-HR curve (Fig. 5) were automatically approximated by linear and non-linear functions, respectively.

To verify the location of AeT and AnT points, the following graphs were analysed simultaneously: $\mathrm{VCO}_{2}-\mathrm{VO}_{2}$ (V-slope method), $\mathrm{HR}-\mathrm{VO}_{2}$ (Conconi method), and PetCO $-\mathrm{VO}_{2}, \mathrm{VE} / \mathrm{VO}_{2}$ vs. load, and $\mathrm{VE} / \mathrm{VCO}_{2}$ vs. load (method of ventilator equivalents). Breath frequency/ $\mathrm{VO}_{2}$ vs. load and $\mathrm{VE}-\mathrm{VO}_{2}$ graphs were automatically plotted for visual analysis. In the course of these examinations, the most likely AeT and AnT points were selected.

The graphs were analysed by at least two independent experts.

To estimate physiological characteristics related to endurance, we used AnT and stroke volume index (SV index) that was

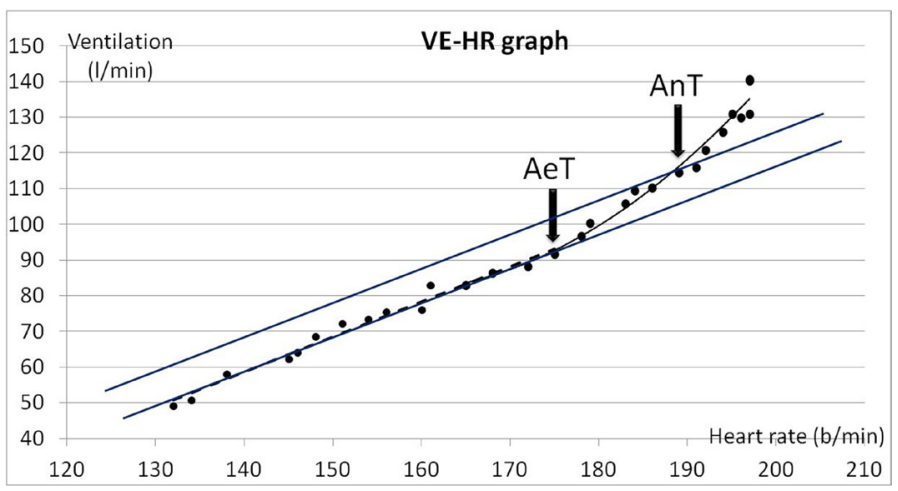

Figure 5. Determination of aerobic (AeT) and anaerobic (AnT) thresholds using VE-HR method calculated using the HR value registered at a standard oxygen consumption of $40 \mathrm{ml} / \mathrm{kg} / \mathrm{min}$ during the treadmill test.

Absolute assessment of specific preparedness in the preparatory period is impossible in winter endurance sports, because it requires specific tests or control competitions so that measurements can be performed in natural snow conditions. Therefore, to monitor athletes' specific preparedness in the preparatory period, we used an integral index of specific preparedness (ISCI or performance index). The calculation of ISCI was based on an assumption that sport-specific athletic capacity is determined by a set of common physical characteristics. The tests which were used in this research provided about 30 parameters related to physical fitness. To calculate ISCI, we used only those $N$ variables which had a significant positive correlation with the athlete's official rank in the Russian Biathlon Union (RBU). Mathematical ISCI is an arithmetic mean of individual physical fitness indicators normalised using a Z-scale and expressed as a percentage of model characteristics of the Russian national team members. The formula for calculating the ISCI index was as follows:

$$
\mathrm{ISCI}=\frac{\sum_{i=1}^{N} Y_{i}}{N}
$$

where $\mathrm{Y}_{\mathrm{i}}=100-\left(\mathrm{X}_{\mathrm{i}}-\mathrm{M}_{\mathrm{i}}\right) / \mathrm{SD}_{\mathrm{i}}^{*}{ }^{*} 100, \mathrm{Y}_{\mathrm{i}}$ is the percentage relative to model value in $\mathrm{i}$-th test, $\mathrm{X}_{\mathrm{i}}$ stands for the percentage relative to model value in the $\mathrm{i}$-th test, $\mathrm{M}_{\mathrm{i}}$ is the model (reference) value in the $\mathrm{i}$-th test for Russian biathletes, and $\mathrm{SD}_{\mathrm{i}}$ is the standard deviation of results in the i-th test for Russian biathletes.

The athletes' state throughout the pre-altitude and altitude training camps was monitored using biochemical parameters including hemoglobin and hematocrit, which reflected changes in the oxygen-carrying capacity of the blood at altitude. Blood parameters were measured in the morning with an empty stomach 4-6 times during a training camp (blood samples were collected from the finger).

\section{Statistical analyses}

All data are presented as mean \pm SD or percentage change. All samples were tested for normal distribution of indicators according to the criteria of asymmetry (As) and excess (Es), as well as for equality of dispersion. Based on the results, it was decided that means would be used to characterise groups. Differences between samples were determined using the MannWhitney-Wilcoxon (MWW) U-test. Statistical significance was set at the level of 0.05. All statistical analyses were made in IBM STATISTICA version 10.0 (StatSoft Inc, USA). As all athletes in the R-team and the B-team used similar training plans and performed nearly the same training load, it was found impossible to 

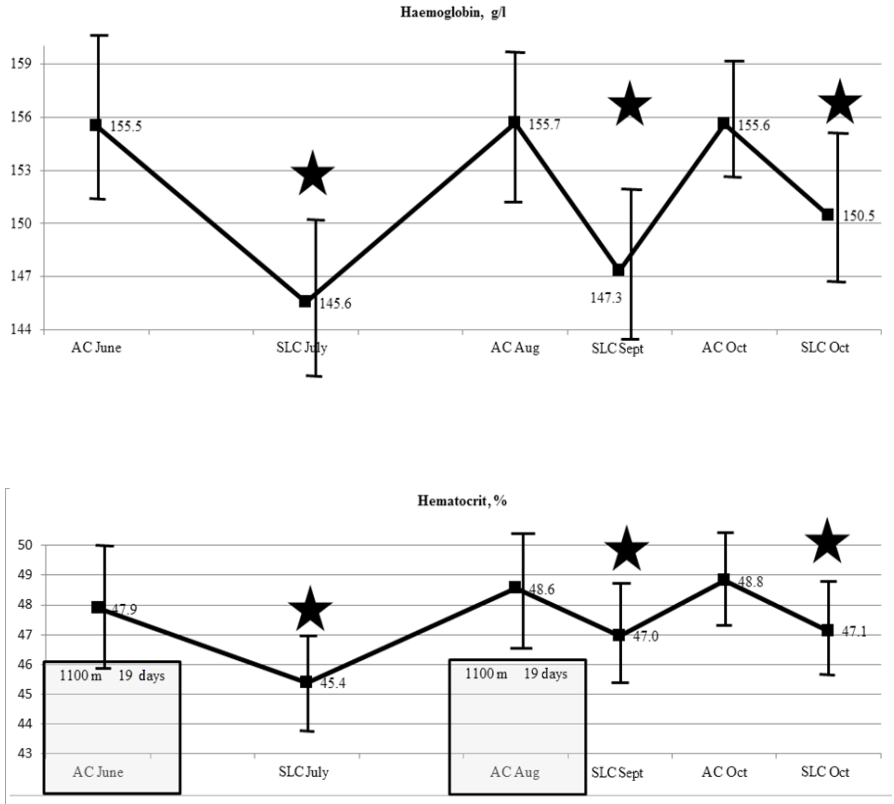

Figure 6. Dynamics of hemoglobin and hematocrit (mean values) during two training stages (B-team) assess the significance of differences. Our practical experience has shown that if a difference in training volume exceeds $10 \%$, it might be considered significant.

Training loads

\section{Results}

The total volume of endurance exercise performed by the R-team at SL differed from that performed at AC by only $2 \%$ (Tab. 2). The B-team performed a considerably greater volume of endurance exercise during AC than SLC (12\% difference), which was primarily due to exercise of low and moderate intensity $(+12 \%$ in zone 1 and $+27 \%$ in zone 2$)$ (Tab. 3$)$. The amount of high-intensity training was also considerably higher $(+35 \%$ in zone 5) in the B-team. When training at altitude, athletes of the R-team performed exercises mostly in the third intensity zone (OBLA zone) and excluded high-intensity workouts from their training plans (zones 4 and 5). Both teams performed a significantly greater volume of strength training at SL (R-team: $+79 \%$; B-team: $+40 \%)$. However, the B-team had a less important decrease in the volume of strength exercise at AC (39\%) than the R-team.

\section{Changes in exercise test}

Power output at OBLA (4 mmol/l, R-team) and VentAnT (B-team) increased considerably. The average value of OBLA in the final test on the rowing ergometer in the R-team was $11.4 \%$ higher than that in the initial test $(p<0.05)$. Average values of VentAnT registered in the final tests in the B-team increased by (a) $11.6 \%(\mathrm{p}<0.05)$ in the SkiErg test and (b) $6.6 \%(\mathrm{p}<0.05)$ in the treadmill test compared with initial test results.

Table 2. Training loads (average per week) in R-team during sea level and altitude camps

\begin{tabular}{|c|c|c|c|c|c|c|c|c|c|}
\hline Training camp & $\begin{array}{l}\text { Endurance } \\
\text { training } \\
(\mathrm{km})\end{array}$ & $\begin{array}{l}\text { Strength } \\
\text { training } \\
\text { (min) }\end{array}$ & $\begin{array}{l}\text { Core } \\
\text { training } \\
\text { (min) }\end{array}$ & $\begin{array}{l}\text { Stretching } \\
\text { (min) }\end{array}$ & $\begin{array}{c}\text { Aerobic } \\
\text { training in } \\
\text { zone } 1(\mathrm{~km})\end{array}$ & $\begin{array}{c}\text { Aerobic } \\
\text { training in } \\
\text { zone } 2(\mathrm{~km})\end{array}$ & $\begin{array}{c}\text { Aerobic- } \\
\text { anaerobic } \\
\text { threshold } \\
(\text { zone } 3, \mathrm{~km})\end{array}$ & $\begin{array}{c}\text { Oxygen } \\
\text { transportation } \\
\text { (zone } 4, \mathrm{~km})\end{array}$ & $\begin{array}{c}\text { Anaerobic } \\
\text { training } \\
(\text { zone } 5, \mathrm{~km})\end{array}$ \\
\hline Sea level camp (1st stage) & 183 & 247 & 28 & 185 & 181 & 0.4 & 0.2 & 1.2 & 0 \\
\hline Altitude camp (2nd stage) & 179 & 153 & 0 & 240 & 176 & 0.66 & 2.3 & 0 & 0 \\
\hline Delta (\%) & 2.4 & 61.1 & 280.0 & -22.9 & 3.1 & -40.0 & -91.4 & 120.0 & 0.0 \\
\hline
\end{tabular}

Intensity zones were determined as percentages of maximal HR and blood lactate: zone 1 - 70-75\% (<2 mmol/l), zone 2 - 75-85\% (2-3.5 mmol/l), zone 3 - 85-90\% (3.5-4 mmol/l), zone 4 - 90-100\% (4-6 mmol/l), and zone 5 - HRmax (6-10 mmol/l).

Table 3. Training loads (average per week) in B-team during first and second training stages

\begin{tabular}{|c|c|c|c|c|c|c|c|c|c|}
\hline Training camp & $\begin{array}{l}\text { Endurance } \\
\text { training }(\mathrm{h})\end{array}$ & $\begin{array}{l}\text { Strength } \\
\text { training } \\
\text { (h) }\end{array}$ & $\begin{array}{l}\text { Core } \\
\text { training } \\
\text { (sets) }\end{array}$ & $\begin{array}{l}\text { Stretching } \\
\text { (h) }\end{array}$ & $\begin{array}{l}\text { Aerobic } \\
\text { training in } \\
\text { zone } 1(h)\end{array}$ & $\begin{array}{c}\text { Aerobic } \\
\text { training in } \\
\text { zone } 2(h)\end{array}$ & $\begin{array}{c}\text { Aerobic- } \\
\text { anaerobic } \\
\text { threshold } \\
(\text { zone } 3, \mathrm{~h})\end{array}$ & $\begin{array}{c}\text { Oxygen } \\
\text { transportation } \\
(\text { zone } 4, \mathrm{~h})\end{array}$ & $\begin{array}{c}\text { Anaerobic } \\
\text { training } \\
(\text { zone } 5, \mathrm{~h})\end{array}$ \\
\hline 1st stage $(A C+S L C)$ & $18: 37$ & $2: 10$ & 19 & $1: 50$ & $12: 09$ & $4: 22$ & $1: 38$ & $0: 24$ & $0: 03$ \\
\hline 2nd stage $(A C+S L C+A C)$ & $21: 15$ & $1: 33$ & 11 & $1: 32$ & $13: 51$ & $5: 58$ & $0: 56$ & $0: 21$ & 0:05 \\
\hline Delta (\%) & -12.3 & 39.7 & 70.3 & 20.1 & -12.3 & -27.0 & 73.7 & 15.6 & -34.9 \\
\hline
\end{tabular}

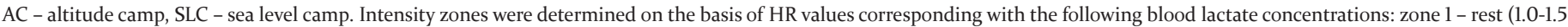
$\mathrm{mmol} / \mathrm{l}$ ), zone 2 - 1.6-2.5 mmol/l, zone 3 - 2.5-4 mmol/l, zone 4 - 4- $6 \mathrm{mmol} / \mathrm{l}$, and zone 5 - 6-10 $\mathrm{mmol} / \mathrm{l}$. 
Table 5. Changes in exercise test results in R-team and B-team

\begin{tabular}{|c|c|c|c|c|c|c|c|c|c|c|}
\hline \multicolumn{5}{|c|}{ R-team } & \multicolumn{6}{|c|}{ B-team } \\
\hline Date & $\begin{array}{c}\text { OBLA } \\
\text { (Wt) }\end{array}$ & HRstand & 2-km race & La max & Date & $\begin{array}{l}\text { VentAnT } \\
\text { upper body } \\
(W t / k g)\end{array}$ & $\begin{array}{c}\text { VentAnT } \\
\text { running } \\
\text { (Wt/kg) }\end{array}$ & SV index & $\begin{array}{l}\text { Performance } \\
\text { Index } \\
\text { (ISCI) }\end{array}$ & La max \\
\hline 09/Nov/2015 & $245 \pm 19$ & $174 \pm 8$ & & & 26/Jun/2016 & $2.75 \pm 0.21$ & $3.9 \pm 0.19$ & $17.7 \pm 1.1$ & & \\
\hline 12/Jan/2016 & $272 \pm 15^{*}$ & $168.5 \pm 5^{*}$ & $6: 49 \pm 0: 19$ & $9.5 \pm 2.1$ & 16/Aug/2016 & $2.87 \pm 0.16$ & $3.89 \pm 0.14$ & $17.8 \pm 1.2$ & $81.4 \pm 5.2$ & $8.6 \pm 0.9$ \\
\hline 03/Mar/2016 & $273 \pm 21^{*}$ & $171 \pm 6$ & $6: 51 \pm 0: 15$ & $11.7 \pm 1.6^{*}$ & 20/Oct/2016 & $3.07 \pm 0.23$ & $4.16 \pm 0.15$ & $18.2 \pm 1.8$ & $87.1 \pm 5.42$ & $10.5 \pm 1.7$ \\
\hline Delta 2-3 (\%) & $11.0^{*}$ & $3.3^{*}$ & & & & 4.4 & 0.3 & 0.6 & & \\
\hline Delta 1-3 (\%) & $11.4^{*}$ & 1.7 & 0.4 & $23.1^{*}$ & & $11.6^{*}$ & $6.7^{*}$ & 2.8 & $7.0^{*}$ & $21.8^{*}$ \\
\hline
\end{tabular}

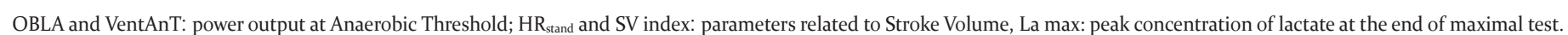
2-km race in R-team and performance index (ISCI) in B-team: parameters correlating with athletic performance.

* $-\mathrm{p}<0.05$ compared with initial test result.

Table 4. Performance and blood lactate concentration in 2-km race

\begin{tabular}{|c|c|c|}
\hline & Pre-altitude test & Post-altitude test \\
\hline Performance & $6: 49.0$ & $6: 50.7$ \\
\hline La max $(\mathrm{mmol} / \mathrm{l})$ & 9.48 & 11.67 \\
\hline
\end{tabular}

La max: maximum blood lactate concentration.

No significant changes were found in indices characterising the cardiovascular system (stroke volume): there was a $1.7 \%$ increase in the R-team ( $\mathrm{p}=0.15)$ and a $2.8 \%$ increase in the B-team $(\mathrm{p}=0.20)$.

The index of specific preparedness (2-km race) did not change in the R-team during the AC $(-0.4 \%, \mathrm{p}>0.05)$; however, the peak lactate concentration in the test increased by $23 \%(\mathrm{p}<0.05)$. Meanwhile, the index of specific preparedness, which had a positive correlation with athletic performance in the B-team, increased by $7 \%(\mathrm{p}<0.05)$, and peak lactate concentration rose by $21.8 \%(\mathrm{p}<0.05)$ in that group.

We have noticed an obvious difference in the overall dynamics of parameters during pre-altitude and altitude training in the R-team and the B-team. All changes in the R-team, including the growth of the HR stand index, were recorded before the start of $A C$, and $A C$ was not characterised by important changes in specific physical fitness. In contrast, all significant changes in the B-team were registered during altitude training.

\section{Discussion}

The R-team and the B-team applied an identical system of calculating the training loads and similar parameters of physical fitness generally accepted in endurance sports (elite rowing and biathlon), which allowed us to analyse the effect of different training methods (at altitude and at sea level) on the parameters of the athletes' functional condition.

The study has shown that the athletes from both teams improved their physical fitness during two stages of the preliminary training period (basic physical training and specific physical training) and demonstrated a similar increase in most specific parameters. The total duration of the preliminary training period was 4-5 months.
However we have found marked differences in the dynamics of aerobic parameters (OBLA and VentAnT) in the R- and B-teams. The most rapid increase in aerobic capacity in the R-team was observed after the SL training camp, while in the B-team, this occurred after the altitude training.

Moreover, no improvement was found for the specific rowing ergometer test ( $2-\mathrm{km}$ race) in the R-team during the AC at $2,280 \mathrm{~m}$. At the same time, B-team athletes demonstrated a significant increase in performance after a training period of the same duration (43 days). This period consisted of two short ACs at 1,100 $\mathrm{m}$ (19 and 11 days) with a 13-day-long stay at SL between them, when the athletes had rest and participated in competitions (2-3 days).

It seems interesting to discuss potential reasons for the differences. The distribution of training loads in the R-team (Fig. 3) was consistent. Separate training blocks were characterised by progressive growth of aerobic loads during SLC and AC; strength and aerobic workouts were spaced out in time. What is important is that strength training during the AC was performed according to a light regimen. The B-team athletes demonstrated no increase in aerobic indices registered at the end of the SL camp in spite of the large volume and high intensity of aerobic training loads during the SL camp. Most probably, low results in aerobic tests were caused by a strength training block performed just prior to the test. In the second training stage $(A C)$, strength training loads were slightly reduced, while the volume of aerobic training was increased, which resulted in the improvement of endurance parameteIt is evident that the R-team and the B-team applied different schemes of hypoxic training. B-team athletes participated in three short ACs (1119 days), whose total duration was 49 days. Athletes from the R-team underwent a single 36-day-long AC. The altitude used for ACs was also different. Two ACs in the B-team were held at $1,100 \mathrm{~m}$, and the third AC was organised according to the "live low $(1,100 \mathrm{~m})$ - train high $(2,800 \mathrm{~m})$ " plan. The athletes performed 5 aerobic training sessions at the altitude of $2,800 \mathrm{~m}$. The athletes from the R-team underwent "live high - train high" training at the altitude of $2,300 \mathrm{~m}$.

Previous studies demonstrated that altitude training is an effective method for stimulating erythrogenesis and increasing hemoglobin mass $[3,4,8]$. However, in the first stage (SL), the R-team performed a large volume of endurance training loads, executed a high percentage of intensive exercises in zone 4 , and did a considerably greater volume of strength exercise. 
This training schedule improved their aerobic capacity after SL. In the second stage (moderate-altitude training), the athletes performed the same total volume of exercise but reduced the volume of strength training by $79 \%$ and excluded all intensive endurance workouts. The coaches expected that physical fitness would be improved due to combination of aerobic training in zone 3 with the effect of natural hypoxia. However, no increase in physical fitness parameters was found. Most probably, the coaches had to decrease the intensity of aerobic training due to high altitude. The volume of strength exercise was also considerably reduced in order to preserve the total volume of training loads. As a result, the athletes demonstrated no increase in aerobic capacity.

Most sport specialists $[1,3,5,6]$ believe that traditional "live high - train high", "live high - train low", or "live high - train high - train low" training protocols do not improve the oxidative capacity of the muscles effectively at the altitude of no more than $2,000 \mathrm{~m}$. The reason is that the capacity of the muscles to consume oxygen at altitude exceeds the capacity of central hemodynamics to transport oxygen (in the case of hypoxemia). This is a phenomenon of functional redundancy in spite of hypothetically higher oxidative stress, which is an activating factor for mitochondrial genes [13].

B-team athletes performed intensive strength exercise and a lower volume of aerobic training in the first training stage (the first AC lasting 19 days and the following SLC lasting 3ldays). This was organised in order to increase the effectiveness of strength training [14]; the greatest part of the training was performed in zone 3 . However, that training scheme did not lead to significant improvement in functional preparedness.

The second stage consisted of two short training camps at moderate altitude (19 and 11 days) and a short recovery period between them (13 days). The total volume of endurance training load was increased at that stage, and so were portions of training in zones 1, 2, and 5. The volume of strength training in the B-team was reduced, but still remained higher than that in the R-team. This training scheme involving moderate hypoxia (30 days at the altitude of $1,100 \mathrm{~m}$ ) resulted in significant growth in all parameters of athletic preparedness. It is of note that training at relatively low altitude $(1,100 \mathrm{~m})$ led to a significant elevation in hemoglobin and hematocrit at each AC (Fig. 6), which might serve as indirect evidence of hemoglobin mass growth. However, some specialists contend that moderate altitude $(1,100 \mathrm{~m})$ and short exposure to hypoxia (11-19 days) is not sufficient for considerable stimulation of erythropoiesis [15].

Thus, we believe that the improvement of B-team athletes' preparedness was equally likely due to: (a) a remote effect of strength training performed at the pre-altitude stage that sometimes exerted potential effect on aerobic capacity and usually improved athletic performance [16]; (b) an optimal ratio between strength and aerobic workouts during the ACs; (c) a higher intensity of aerobic work at the end of the specific preparation period, which usually has a positive effect on sportspecific physical preparedness [17]; (d) an improvement in the oxygen transport function of the blood, which is considered to be the main and the most common positive effect of moderatealtitude training [18].

\section{Conclusion}

Monitoring of elite athletes' training in the preparatory period showed positive changes in physical preparedness in both groups. We found that those positive changes might not be related to an additional effect of natural hypoxia. Our study has shown that rational and well balanced planning according to training goals is the key factor in the improvement of general and specific athletic preparedness. In other words, in spite of considerable evidence of a positive effect of training under natural or artificial hypoxia on crucial physiological functions, the improvement of athletic performance to a large extent depends on the knowledge and experience of coaches and the ability of athletes to estimate their state and adjust training loads according to their condition.

\section{Acknowledgements}

This work was supported by the Department of Science and Education (No. SB/EMEQ-153/2013) of the Ministry of Sport of the Russian Federation, the Technology Division of the Science and Education Department, as well as the General Administration of Sport of China. The work was completed based on a decision of the Russian-Chinese workgroup on joint scientific research in elite sport.

\section{Literature}

1. Chapman R.F., Stray-Gundersen J., Levine B.D. (1998). Individual variation in response to altitude training. Journal of Applied Physiology 85(4), 1448-1456. DOI: 10.1152/ jappl.1998.85.4.1448.

2. Bakkman L., Sahlin K., Holmberg H.C., Tonkonogi M. (2007). Quantitative and qualitative adaptation of human skeletal muscle mitochondria to hypoxic compared with normoxic training at the same relative work rate. Acta Physiology (Oxford) 190, 243-251. DOI: 10.1111/j.17481716.2007.01683.x.

3. Friedmann-Bette B. (2008). Classical altitude training. Scandinavian Journal of Medicine and Science in Sports 18 (1), 11-20. DOI: 10.1111/j.1600-0838.2008.00828.x.

4. Bonetti D.L., Hopkins W.G. (2009). Sea-Level Exercise performance following adaptation to hypoxia. A meta-analysis. Sports Medicine 39 (2), 107-127. DOI: 10.2165/00007256200939020-00002.

5. Millet G.P., Roels B., Schmitt L., Woorons X., Richalet J.P. (2009). Combining hypoxic methods for peak performance. Sports Medicine 40(1), 1-25. DOI: 10.2165/11317920000000000-00000.

6. Vogt M., Hoppeler H. (2010). Is hypoxia training good for muscles and exercise performance? Progress in Cardiovascular Diseases 52, 525-533. DOI: 10.1016/j.pcad.2010.02.013.

7. Lundby C., Millet G.P., Calbet J.A., Bartsch P., Subudhi A.W. (2012). Does 'altitude training' increase exercise performance in elite athletes? British Journal of Sports Medicine 46(11), 792-795. DOI: 10.1136/bjsports-2012-091231.

8. Chapman R.F. (2013). The individual response to training and competition at altitude. British Journal of Sports Medicine 47(1), 40-44. DOI: 10.1136/bjsports-2013-092837.

9. Chapman R.F., Stickford A.L., Lundby C., Levine B.D. (2014). Timing of return from altitude training for optimal sea level performance. Journal of Applied Physiology 116(7), 837-843. DOI: 10.1152/japplphysiol.00663.2013.

10. Faiss R., Willis S., Born D.P., Spelich B., Vesin J.M., Holmberg H.C. et al. (2015). Repeated double-poling sprint training in hypoxia by competitive cross-country skiers. Medicine and Science in Sports and Exercises 47(4), 809-817.

11. Bădău D., Bacârea A., Ungur R.N., Bădău A., Martoma A.M. (2016). Biochemical and functional modifications in biath- 
lon athletes at medium altitude training. Revista Romana de Medicina de Laborator 24(3), 327-335.

12. Gore C.J. (2014). The challenge of assessing athlete performance after altitude training. Journal of Applied Physiology 116, 593-594. DOI: 10.1152/japplphysiol.00029.2014.

13. Lewis N.A. (2015). Alterations in redox homeostasis in the elite endurance athlete. Sports Medicine 45(3), 379-409. DOI: $10.1007 / \mathrm{s} 40279-014-0276-5$.

14. Murach K.A, Bagley J.R. (2016). Skeletal muscle hypertrophy with concurrent exercise training: Contrary evidence for an interference effect. Sports Medicine 46(8), 1029-39. DOI: 10.1007/s40279-016-0496-y.

15. Chapman R.F.T., Karlsen, G.K., Resaland R.L., Ge M.P., Harber S. et al. (2014). Defining the "dose" of altitude training: how high to live for optimal sea level performance enhance- ment. Journal of Applied Physiology 116(6), 595-603. DOI: 10.1152/japplphysiol.00634.2013.

16. Beattie K., Kenny I.C, Lyons M, Carson B.P. (2014). The effect of strength training on performance in endurance athletes. Sports Medicine 44(6), 845-865. DOI: 10.1007/ s40279-014-0157-y.

17. Tønnessen E, Sylta Ø, Haugen T.A, Hem E, Svendsen I.S. et al. (2014) The road to gld: Training and peaking characteristics in the year prior to a gold medal endurance performance. PLoS ONE 9(7): el01796.

18. Czuba M., Maszczyk A., Gerasimuk D., Roczniok R., FidosCzuba O., Zając A. et al (2014). The effects of hypobaric hypoxia on erythropoiesis, maximal oxygen uptake and energy cost of exercise under normoxia in elite biathletes Journal of Sports Science and Medicine 13, 912-920.

Submitted: August 8, 2018.

Accepted: February 26, 2019. 